\title{
Quality of Life of Bulgarian Breast Cancer Female Patients
}

\author{
Galina Yaneva ${ }^{1}$, Tsonka Dimitrova ${ }^{1}$, Dobri Ivanov ${ }^{1}$, Gergana Ingilizova $^{2}$, Sergei Slavov $^{3,4 *}$ (D) \\ ${ }^{1}$ Department of Biology, Faculty of Pharmacy, Medical University "Prof. Dr. Paraskev Stoyanov", Varna, Bulgaria; ${ }^{2}$ Multiprofile \\ Hospital for active Treatment "Vita", Sofia, Bulgaria, ${ }^{3}$ University Hospital of Obstetrics and Gynecology "Maichin Dom", Sofia, \\ Bulgaria; ${ }^{4}$ Department of Obstetrics and Gynecology, Medical University, Sofia, Bulgaria
}

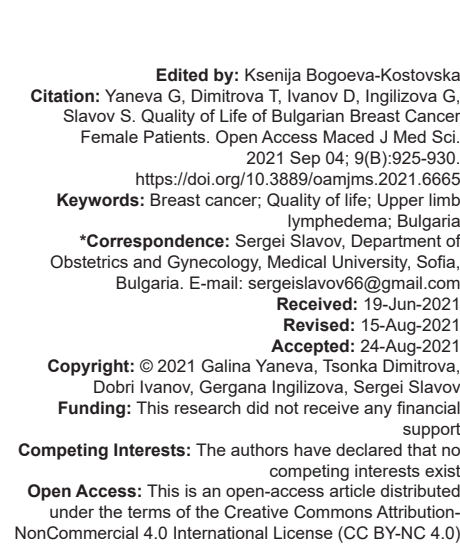

Introduction

According to a status report on the global burden of cancer worldwide using the GLOBOCAN 2018 estimates of cancer incidence and mortality produced by the International Agency for Research on Cancer focusing on geographic variability across 20 world regions, breast cancer is the most commonly diagnosed cancer and the leading cause of cancer death in females [1]. Recent data of Globocan 2020 demonstrate that the number of new breast cancer cases in Bulgaria in 2020 is 4061 or $11.14 \%$ of all the new cancer cases and $25.46 \%$ of all the new female cancer cases [2], [3], [4]. Breast cancer occupies the first place among female cancers. The age-standardized (world) incidence rate of female breast cancer in Bulgaria in 2020 is 60.0 per 100,000 population. The number of deaths is 1,533 , the mortality rate is $7.88 \%$ of all the cancer deaths, and the age-standardized (world) mortality rate is 16.7 per 100,000 population thus occupying the second place after lung cancer.

\begin{abstract}
BACKGROUND: During recent years, breast cancer is the most commonly diagnosed cancer and the leading cause (QoL) after treatment represent undoubted interest and contribute to the elaboration and implementation of specific

AIM: The objective of the present study was to

MATERIALS AND METHODS: We examined a total of 57 female breast cancer patients operated on between 2018 questionnaire containing 27 items.

RESULTS: There was a significant prevalence of the ductal carcinoma and nonspecific invasive carcinoma, of patient's responses to one and the same question when all 27 questions of all 57 patients were assessed as a whole. The response with "a little" inclination dominated concerning the psychological dimension. The responses with "a your professional relationships") considerably prevailed indicating the pronounced unfavourable influence on these

( contribute to the improvement of patient's life characteristics.
\end{abstract}

Breast-cancer-related lymphedema (BCRL) is a common condition among breast cancer survivors that could impact patient's quality of life (QoL) [5]. In an updated overview of lymphedema-specific questionnaires available from MEDLINE (via Ovid), EBSCOhost, PubMed, Scopus, and Web of Science databases used in the BCRL population, the most valid and reliable QoL questionnaire for clinical and research use are recommended.

The 14-item Upper Limb Lymphedema QoL scale that is derived from a pool of 98 items generated by breast cancer patients is a robust upper limb lymphedema-specific measure that is feasible and valid to use in clinical and research settings [6]. The validation of a condition-specific QoL measure for lymphoedema of the limbs can be used routinely in clinical services [7], [8]. It covers four domains: symptoms, body image/appearance, function, and mood, as well as an overall QoL score.

The objective of the present study was to assess some aspects of the QoL in female patients 
with breast cancer following successful disease management.

\section{Materials and Methods}

Our study covered a total of 57 female breast cancer patients operated on between 2018 and 2020 in Marko Markov Specialized Hospital for Active Treatment of Oncological Diseases of Varna, Bulgaria. Their mean age was $47.89 \pm 6.71$ years (range, 30-59 years). Some of their tumor characteristics were studied. They filled in independently and anonymously the upper limb lymphoedema QoL questionnaire (ULL-QoL) containing 27 items [9] translated in Bulgarian. Their responses were statistically evaluated.

This specific QoL self-completed questionnaire has been constructed in English and validated for the assessment of the changes in QoL on treatment [9]. The final scale is defined by 27 items and three dimensions: physical (14 questions), psychological (seven questions), and social (six questions). There are three possible digital responses to each question: 1 ("not at all"), 2 ("a little") and 3 ("a lot"). The authors claim that symptoms in these domains are better indicators of patient's well-being as well as specific quality of this life scale reflects appropriately and completely all the possible impact of the lymphoedema in the women's daily life.

\section{Physical dimension}

Have you suffered problems

(1) Because of a swollen arm, (2) a heavy arm (3) pins and needles (4) a swollen skin, (5) in going to sleep, (6) washing yourself, (7) picking up objects, (8) sleeping, (9)walking, (10) using public transport, (11) dressing, (12) remaining in certain positions, (13) holding, and (14) seizing things from a certain height.

\section{Psychological dimension}

Are you prone

(1) To becoming angry, (2) feeling sad, (3) lacking confidence in yourself, (4) lacking confidence in the future, (5) feeling well in yourself, (6) feeling low, and (7) feeling distressed.

\section{Social dimension}

Are you disturbed when you

(1) Go to a restaurant, (2) go out in the sun, (3) go on holiday, (4) look at yourself in a mirror, (5) in your emotional life with your partner, (6) in your professional relationships.
We have further divided the group of the physical dimension into two subgroups., i.e., healthrelated complaints (four items) and activities of daily living (ten items).

\section{Health-related complaints}

(1) Because of a swollen arm, (2) a heavy arm (3) pins and needles (4) a swollen skin.

\section{Activities of daily living}

(1) In going to sleep, (2) washing yourself, (3) picking up objects, (4) sleeping, (5) walking, (6) using public transport, (7) dressing, (8) remaining in certain positions, (9) holding, and (10) seizing things from a certain height.

\section{Results}

Patient's distribution according to age groups was demonstrated in Table 1. Most of them were aged below 49 years that proved the social significance of this malignant disease.

Table 1: Patient's distribution according to age groups

\begin{tabular}{|c|c|c|c|}
\hline \multicolumn{4}{|c|}{ Age groups } \\
\hline \multicolumn{2}{|c|}{$40-49$ years } & \multicolumn{2}{|c|}{$50-59$ year } \\
\hline $\mathrm{n}$ & $\%$ & $\mathrm{n}$ & $\%$ \\
\hline 33 & 57.90 & 24 & 42.10 \\
\hline
\end{tabular}

Patient's distribution according to breast cancer histological types and molecular phenotypes, on the one hand, and four differentiation grades used by clinical pathologists in Bulgaria, on the other hand, were presented in Tables 2 and 3, respectively. There was a significant prevalence of the ductal carcinoma and nonspecific invasive carcinoma as well as of the luminal B-human epidermal growth factor receptor-2 (HER2) positive and luminal B-HER2 negative breast cancer. The frequency of the basocellular (triple-negative breast cancer) was relatively high (14.04\% of the cases). Grade two of differentiation considerably dominated, indeed.

Table 2: Histological types and differentiation grades of breast cancer patients

\begin{tabular}{llllll}
\hline Histological type & G1 & G2 & G3 & G4 & Total \\
\hline Ductal carcinoma & - & 22 & 9 & 1 & 32 \\
Nonspecific invasive carcinoma & 1 & 9 & 5 & - & 25 \\
Not otherwise specified breast cancer & - & 5 & - & - & 5 \\
Lobular carcinoma & - & 1 & - & 1 & 2 \\
Invasive ductal carcinoma & - & 1 & 1 & - & 2 \\
Noninvasive carcinoma & - & 1 & - & - & 1 \\
Total - $n$ & - & 39 & 15 & 2 & 57 \\
Total - \% & 1.75 & 68.42 & 26.32 & 3.51 & 100.00 \\
\hline
\end{tabular}

The number and relative share of three different responses of breast cancer patients to the questions of these four QoL dimensions were shown in Table 4. As a whole, the responses with "not at all" dominated being 
Table 3: Molecular phenotypes and differentiation grades of breast cancer patients

\begin{tabular}{llllll}
\hline Molecular phenotype & G1 & G2 & G3 & G4 & Total \\
\hline Luminal B-HER2 positive & - & 20 & 2 & 1 & 23 \\
Luminal B - HER2 negative & 1 & 14 & 6 & - & 21 \\
Basocellular (triple-negative breast cancer) & - & 4 & 3 & 1 & 8 \\
Non-luminal HER2 positive & - & 1 & 3 & - & 4 \\
Luminal A & - & - & 1 & - & 1 \\
Total - n & 1 & 39 & 15 & 2 & 57 \\
Total - \% & 1.75 & 68.42 & 26.32 & 3.51 & 100.00 \\
\hline HER-2: Human epidermal growth factor receptor-2. & & & & &
\end{tabular}

particularly prevailing concerning two domains such as "activities of daily living" and "health-related complaints. On the other hand, the responses with "a little" dramatically dominated concerning the psychological dimension. The responses with "a lot" were relatively common concerning the social dimension only thus indicating a real unfavorable influence on patient's quality of social life of the malignant neoplasm.

Table 4: Number and relative share of three different responses of breast cancer patients

\begin{tabular}{|c|c|c|c|c|c|c|}
\hline \multirow[t]{2}{*}{ Group of questions } & \multicolumn{2}{|c|}{$\begin{array}{l}\text { Response 1- } \\
\text { "not at all" }\end{array}$} & \multicolumn{2}{|c|}{$\begin{array}{l}\text { Response 2 - } \\
\text { "a little" }\end{array}$} & \multicolumn{2}{|c|}{$\begin{array}{l}\text { Response 3- } \\
\text { "a lot" }\end{array}$} \\
\hline & $\mathrm{n}$ & $\%$ & $\mathrm{n}$ & $\%$ & $\mathrm{n}$ & $\%$ \\
\hline Health-related complaints & 134 & 58.77 & 93 & 40.79 & 1 & 0.44 \\
\hline Activities of daily living & 425 & 74.56 & 122 & 21.40 & 23 & 4.04 \\
\hline Psychological dimension & 47 & 11.78 & 306 & 76.69 & 46 & 11.53 \\
\hline Social dimension & 161 & 47.08 & 72 & 21.05 & 109 & 31.87 \\
\hline Total & 767 & 49.84 & 593 & 38.53 & 179 & 11.63 \\
\hline
\end{tabular}

The distribution of the number of breast cancer patients according to the number and relative share of their three single different responses to all the questions was summarized in Table 5. It was noteworthy that 50 responses with "not at all" were given by five patients each, 47 responses - by three patients each, and 41 responses - by one patient only. Besides, 47 responses with "a little" were given by two patients each, and 43 responses were given by four patients each.

Table 5: Number of breast cancer patients, number and relative share of their three single responses to all the questions

\begin{tabular}{|c|c|c|c|c|c|c|}
\hline \multirow{3}{*}{$\begin{array}{l}\text { Number of patients } \\
\text { with responses }\end{array}$} & \multicolumn{6}{|c|}{ Total number of patients' single responses to all the questions } \\
\hline & \multicolumn{2}{|c|}{$\begin{array}{l}\text { Response 1- } \\
\text { "not at all" }\end{array}$} & \multicolumn{2}{|c|}{$\begin{array}{l}\text { Response 2 - "a } \\
\text { little" }\end{array}$} & \multicolumn{2}{|c|}{$\begin{array}{l}\text { Response 3- } \\
\text { "a lot" }\end{array}$} \\
\hline & $\mathrm{n}$ & $\%$ & $\mathrm{n}$ & $\%$ & $\mathrm{n}$ & $\%$ \\
\hline By 15 patients each & - & - & - & - & 3 & 8.33 \\
\hline By 13 patients each & 15 & 7.94 & - & - & - & - \\
\hline By 10 patients each & - & - & - & - & 4 & 11.11 \\
\hline By 9 patients each & - & - & - & - & 2 & 5.56 \\
\hline By 8 patients each & - & - & 14 & 8.81 & - & - \\
\hline By 7 patients each & 13 & 6.88 & - & - & - & - \\
\hline By 6 patients each & - & - & 19 & 11.95 & - & - \\
\hline By 5 patients each & 50 & 26.45 & - & - & 6 & 16.67 \\
\hline By 4 patients each & - & - & 43 & 27.04 & 6 & 16.67 \\
\hline By 3 patients each & 47 & 24.87 & 31 & 19.50 & - & - \\
\hline By 2 patients each & 23 & 12.17 & 47 & 29.56 & 7 & 19.44 \\
\hline By 1 patient only & 41 & 21.69 & 5 & 3.14 & 8 & 22.22 \\
\hline $\begin{array}{l}\text { Total number of } \\
\text { responses }\end{array}$ & 189 & 100.00 & 159 & 100.00 & 36 & 100.00 \\
\hline
\end{tabular}

There was a great variety of the frequency of different patient's responses to one and the same question when all 27 questions of all 57 patients were assessed as a whole. Patient's distribution according to the total number of variants of their responses and to their total corresponding number to all these questions was shown in Table 6 . There were four variants of responses by one patient only and by five patients each resulting in a total of 41 and 50 single responses with "not at all" as well as three variants of such responses by three patients resulting in a total of 47 single responses. Besides, there were four variants of responses by four patients with "a little" resulting in a total of 43 single responses as well as three variants of such responses by two patients resulting in a total of 47 single responses.

Table 6: Patient's distribution according to the total number of variants of responses and their total corresponding number to all the questions

\begin{tabular}{|c|c|c|c|c|c|c|}
\hline \multirow{2}{*}{$\begin{array}{l}\text { Number of } \\
\text { patients with } \\
\text { responses }\end{array}$} & \multicolumn{2}{|c|}{$\begin{array}{l}\text { Response 1 - "not } \\
\text { at all" }\end{array}$} & \multicolumn{2}{|c|}{ Response 2 - "a little" } & \multicolumn{2}{|c|}{ Response 3 - "a lot" } \\
\hline & Variants & Responses & Variants & Responses & Variants & Responses \\
\hline One & 4 & 41 & 1 & 5 & 1 & 8 \\
\hline Two & 2 & 23 & 3 & 47 & 1 & 7 \\
\hline Three & 3 & 47 & 2 & 31 & - & - \\
\hline Four & - & - & 4 & 43 & 2 & 6 \\
\hline Five & 4 & 50 & - & - & 1 & 6 \\
\hline Six & - & - & 2 & 19 & - & - \\
\hline Seven & 1 & 13 & - & - & - & - \\
\hline Eight & - & - & 2 & 14 & - & - \\
\hline Nine & - & - & - & - & 1 & 2 \\
\hline Ten & - & - & - & - & 10 & 4 \\
\hline Thirteen & 1 & 15 & - & - & - & - \\
\hline Fifteen & - & - & - & - & 1 & 3 \\
\hline Total & 15 & 189 & 14 & 159 & 17 & 36 \\
\hline
\end{tabular}

Besides we analyzed some items presenting with the greatest and smallest number and relative share of the patients responding either with "not at all", "a little", or "a lot" in these four dimensions. It stressed that there was only one response with suffering "a lot" given to all the four items dealing with health-related complaints. There were 40 responses suffering "not at all" $(70.16 \%)$ and 16 one suffering 'a little' $(28.07 \%$ of the cases) to item number one (suffering because of a swollen arm).

Within the domain of the affected activities of daily living, all the patients responded with "not at all" to the item six (using public transport); 53 patients $(92.98 \%)$ did to the items number two (washing yourself), and number five (walking) each; 52 patients $(91.23 \%)$ did to the item number three (picking up objects), and 51 patients (89.47\% of the cases) did to the item number nine (holding). On the other hand, there were no responses "a lot" given to seven of these 10 items of this domain. The response with "a little" prevailed in item number four (sleeping) given by 34 patients $(59.65 \%)$ and item number one (going to sleep) given by 31 patients (54.39\% of the cases).

Concerning the psychological dimension, the total domination of the response with "a little" inclination should be outlined. Some 51 patients $(89.47 \%)$ gave this response to item number five (feeling well in yourself) while 50 patients $(87.72 \%$ of the cases) did to items number one (becoming angry), number six (feeling low), and number seven (feeling distressed) each.

Within the domain of social dimension, there were no responses with "a lot" disturbance given to item numbers one (go to a restaurant), two (go out in the sun), and three (go on holiday). Some 53 patients (92.98\%) responded with "not at all" disturbance to the latter item. The responses with "a lot" disturbance considerably prevailed in terms of the last three items, i.e., in terms 
of item number five (in your emotional life with your partner), item number four (look at yourself in a mirror), and item number six (in your professional relationships) given by 39 patients $(68.42 \%), 36$ patients $(63.16 \%)$, and 34 patients (59.65\% of the cases), respectively. Obviously, the unfavorable influence on patients' QoL was most pronounced when these three aspects of social life were concerned.

Our results convincingly demonstrated that the damaging effect on the individual QoL parameters of the female breast cancer patients in our contingent of this severe disease was relatively moderately expressed. This could be due to the successful application of timely and adequate diagnostic and integrated therapeutic behaviour.

\section{Discussion}

Our results from the examination of some aspects of the QoL of 57 women with breast cancer in the city of Varna are similar to those recently reported by authors from different countries worldwide.

Using the histotechnical method of largeformat histology in 215 breast neoplasm patients, invasive carcinoma of no special type in 122 , ductal carcinoma in situ in 46, and lobular carcinoma in 28 cases have most commonly been identified [10]. Patients with ductal carcinoma in situ at early-stage or locally advanced breast cancer present with increased symptom burden and decreased QoL examined by means of the Edmonton Symptom Assessment System and the Functional Assessment of Cancer Therapy for Breast Cancer [11].

The consensus-based version of the Italian version of the Lymphedema QoL Questionnaire for upper limbs that have been was administered to 139 patients with upper-limb stable secondary iatrogenic lymphedema after breast cancer is reliable, sensitive to change, and valid and thus it can be used for clinical and research purposes [12].

In a cross-sectional study of 400 breast cancer survivors, pain inversely correlates with QoL in $71.7 \%$ of the cases [13]. Breast cancer is associated with decreased functional capacity and compromized QoL in women with locoregional and distant metastases compared to those without metastasis [14], [15].

Long-term physical changes in women surviving breast cancer include anatomic changes, chronic pain, phantom breast pain, axillary web syndrome, lymphedema as well as decreased strength, aerobic capacity, mobility, fatigue, and cognitive dysfunction [16]. Their emotional and psychosocial changes include depression, anxiety, fatigue, concerns about body image, and issues with sexuality.
The results from the study of the mediating role of cognitive emotion regulation strategies in relation between emotional distress and various aspects of QoL of 97 breast cancer patients demonstrate that positive refocusing, rumination, and catastrophizing are significant cognitive coping strategies which significantly change emotional distress intensity and improve patients' QoL [17].

The sexual functions of 25 female patients with lymphedema and 20 ones without lymphedema after total mastectomy are evaluated by Female Sexual Function Index while their QoL is assessed by European Organization for Research and Treatment of Cancer QoL Questionnaire Core 30 [18]. Both sexual functions and QoL are adversely affected in patients who undergo mastectomy and develop lymphedema.

In 170 female breast cancer patients 1 month before and after surgical treatment, there are statistically significant differences in the QoL domains of sexual functioning and sexual enjoyment between younger and older women independently of surgery [19], [20]. The surgical treatment negatively affects the QoL independently of age.

In a cross-sectional study, health-related QoL and upper limb function in 54 breast cancer-related lymphedema patients are estimated [21]. The score for mental health is higher than that for physical one $(47.0 \pm 12.2$ vs. $42.2 \pm 7.5)$. The domains of mental health $(67.7 \pm 22.9)$ and social function $(70.1 \pm 23.1)$ are with the highest values while those of physical role $(46.9 \pm 39.1)$ and general health $(49.3 \pm 20.1)$ are with the lowest scores. Upper extremity function statistically significantly correlates with the domains of physical role, bodily pain, physical composite summary, and emotional role $(p<0.01)$

The health-related QoL of 200 Egyptian female breast cancer patients is measured using the functional assessment of cancer therapy-breast for patients with lymphedema in the medical oncology outpatient clinic between December 2015 and March 2018 [22]. The median assessment score is 81 (range 35-133). The medians of subscales are the following: Physical well-being 13 (range 0-28), social well-being 20 (range 0-28), emotional well-being 15 (range 2-24), and functional well-being 16 (range 2-28).

Of 834 breast cancer survivors, 13\% have symptom clusters of pain, fatigue, and psychological distress [23]. Younger age $(p=0.003)$, lymphedema ( $p=0.02)$, working part-time $(p<0.001)$, or being disabled $(p<0.001)$ are associated with the symptom clusters. A multiple-case study of a total of 13 female breast cancer survivors with breast cancer-related lymphedema reveals the following four main themes [24], [25]: (i) Breast cancer-related lymphedema affects physical and emotional functioning associated with work; (ii) ongoing treatment for this disorder creates challenges for work; (iii) environmental factors 
affect the return-to-work experience; and (iv) personal factors play a key role in adjusting to return-to-work.

In 54 breast cancer patients with lymphedema who have completed the Lymphedema QoL Questionnaire, lymphedema severity does not impact their QoL and the International Society of Lymphology staging may not be used alone to describe this severity [26], [27].

\section{Conclusion}

Our study of a relatively small patient's sample demonstrated a moderately expressed unfavorable influence on individual QoL of the breast cancer following treatment. Future research of a larger contingent additionally using some other specific questionnaires and focusing on the emotional and social aspects of the QoL could contribute to the improvement of patient's life characteristics.

\section{References}

1. Bray F, Ferlay J, Soerjomataram I, Siegel RL, Torre LA, Jemal A. Global cancer statistics 2018: GLOBOCAN estimates of incidence and mortality worldwide for 36 cancers in 185 countries. CA Cancer J Clin. 2018;68(6):394-424. https://doi. org/10.3322/caac. 21492

PMid:30207593

2. International Agency for Research on Cancer. The Global Cancer Observatory. Lyon: International Agency for Research on Cancer; 2020.

3. Kostov I, Ivanov S. Prevention and prophylaxis in obstetrics and gynecology. Akush Ginekol. 2018;57(2):57-8.

4. Georgiev S, Savov A, Kostova P, Frandeva B, Kostov I, Zlatkov V. Frequency and characteristic of HPV cervical infection during pregnancy and postpartum and the role of smoking as a predisposing factor. CR Acad Bulg Sci. 2019;72(4):551-8. https://doi.org/10.7546/crabs.2019.04.17

5. Meilani E, Zanudin A, Nordin NA. Psychometric properties of quality of life questionnaires for patients with breast cancerrelated lymphedema: A protocol for a systematic review. Medicine (Baltimore). 2020;99(52):e23897. https://doi. org $/ 10.1097 / \mathrm{md} .0000000000023897$

PMid:33350786

6. Williams AE, Rapport F, Russell IT, Hutchings HA. Psychometric development of the upper limb lymphedema quality of life questionnaire demonstrated the patient-reported outcome measure to be a robust measure for breast cancer-related lymphedema. J Clin Epidemiol. 2018;100:61-70. https://doi. org/10.1016/j.jclinepi.2018.04.014

PMid:29723583

7. Keeley V, Crooks S, Locke J, Veigas D, Riches K, Hilliam R. A quality of life measure for limb lymphoedema (LYMQOL). J Lymphol. 2010;5(1):26-37.

8. Kostov I. Assessment of the Impact of Medical Standard in
Obstetrics and Gynaecology: Organizational, Clinical and DEONTOLOGICAL ASPECTS. Doctoral Thesis. Varna: Medical University of Varna; 2017.9.

9. Launois R, Alliot F. Quality of life scale in upper limb lymphoedema-a validation study. Lymphology. 2000;33:266-74.

10. Ivkovic-Kapicl T, Vicko F, Djilas D, Tot T. Large-format histology in diagnosing breast carcinoma. Vojnosanit Pregl. 2020;77(9):986-91. https://doi.org/10.2298/vsp180515166i

11. Hamer J, McDonald R, Zhang L, Verma S, Leahey A, Ecclestone C, et al. Quality of life (QOL) and symptom burden (SB) in patients with breast cancer. Support Care Cancer. 2017;25(2):409-19. https://doi.org/10.1007/s00520-016-3417-6 PMid:27696078

12. Monticone M, Ferriero G, Keeley V, Brunati R, Liquori V, Maggioni $\mathrm{S}$, et al. Lymphedema quality of life questionnaire (LYMQOL): Cross-cultural adaptation and validation in Italian women with upper limb lymphedema after breast cancer. Disabil Rehabil. 2021;2021.1-6. http://doi.org/10.1080/09638288.2021. 1890842

PMid:33651953

13. Costa WA, Monteiro MN, Queiroz JF, Gonçalves AK. Pain and quality of life in breast cancer patients. Clinics (Sao Paulo). 2017;72(12):758-63. https://doi.org/10.6061/clinics/2017(12)07 PMid:29319722

14. Costa WA, Eleutério J Jr., Giraldo PC, Gonçalves AK. Quality of life in breast cancer survivors. Rev Assoc Med Bras (1992). 2017a;63(7):583-9. https://doi. org/10.1590/1806-9282.63.07.583 PMid:28977083

15. Delchev $\mathrm{Y}$, Kostov I, Totsev R. Tumors in retroperitoneal area. Clinical case. Akush Ginekol. 2018;57(4):33-7.

16. Lovelace DL, McDaniel LR, Golden D. Long-term effects of breast cancer surgery, treatment, and survivor care. J Midwifery Womens Health. 2019;64(6):713-24. https://doi.org/10.1111/ jmwh.13012 PMid:31322834

17. Kovac A, Tovilovic S, Ignjatovic VB, Popovic-Petrovic S, Tatic M The role of cognitive emotion regulation strategies in health related quality of life of breast cancer patients. Vojnosanit Pregl. 2020;77(10):1032-40. https://doi.org/10.2298/vsp180205178k

18. Mülkoğlu C, Ayhan F, Erel S. Sexual functions and quality of life in patients developing lymphedema after total mastectomy: A pilot study. Lymphat Res Biol. 2021. http://doi,org/10.1089/ Irb.2020.0053

PMid:33646047

19. Kostic S, Murtezani Z, Andric Z, Ivanovic N, Kozomara Z, Kostic $M$, et al. Assessment of age-related influences on the quality of life of breast cancer patients before and after surgical treatment. Vojnosanit Pregl. 2020;77(9):908-16. https://doi. org/10.2298/vsp180629155k

20. Kostov I, Vasilev N, NachevaA, Lazarov I. Radical trachelectomysurgery for preserving woman's fertility in patients with invasive cervical cancer. Akush Ginekol. 2013;52(7):27-30.

PMid:24505637

21. Bojinović-Rodić D, Popović-Petrović S, Tomić S, Markez S, Živanić D. Upper extremity function and quality of life in patients with breast cancer related lymphedema. Vojnosanit Pregl. 2016;73(9):825-30. https://doi.org/10.2298/vsp150208075b PMid:29320146

22. Khater Al, Noaman MK, Abdel Hafiz MN, Moneer MM, Elattar IA. Health-related quality of life among Egyptian female breast cancer patients at the National Cancer Institute, Cairo University. Asian Pac J Cancer Prev. 2019;20(10):3113-9. https://doi.org/10.31557/apjcp.2019.20.10.3113

PMid:31653162 
23. Bjerkeset E, Röhrl K, Schou-Bredal I. Symptom cluster of pain, fatigue, and psychological distress in breast cancer survivors: Prevalence and characteristics. Breast Cancer Res Treat. 2020;180(1):63-71. https://doi.org/10.1007/ s10549-020-05522-8

PMid:31938939

24. Sun $Y$, Shigaki CL, Armer JM. The influence of breast cancer related lymphedema on women's return-to-work. Womens Health (Lond). 2020;16:1745506520905720. http://doi. org/10.1177/1745506520905720

PMid:32293984.

25. Nedyalkov K, Magunska N, Bechev B, Kostov I. Survival rate and complications after different type of pelvic exenterations for gynecological cancer. EJGO Eur J Gynaecol Oncol. 2019;40(1):69-73.

26. Lee TS, Morris CM, Czerniec SA, Mangion AJ. Does lymphedema severity affect quality of life? Simple question. Challenging answers. Lymphat Res Biol. 2018;16(1):85-91. https://doi.org/10.1089//rb.2016.0049

PMid:28453410

27. Kostov I, Yunakova M, Georgiev B, Petrova Z. Analysis of the quality of medical services in obstetrics and gynecology practice in Bulgaria-a study in organizational, clinical and deontological aspects. Akush ginekol. 2017;56(6):9-16. 